\title{
Effectiveness of the Reinforcement Parent Education Program Designed for Parents of Children with Autism Spectrum Disorder on Supporting Positive Behaviours
}

\section{Ahsen Ela KIZILKAYA ${ }^{1 \rtimes}$ Hakan SARI ${ }^{2}$}

'Dr, Karamanoglu Mehmetbey University, Special Education Department, Karaman, Turkey. Email:ahsenkizillaya@gmail.com Tel:+90537551805s

${ }^{2}$ Prof. Dr., Konya Necmettin Erbakan University, Special Education Department, Konya, Turkey. Email:hakansari@gmail.com Tel:+905053467401

\section{Abstract}

This study aims to examine the effect of the Effective Reinforcement Use Parent Education Program, which was developed for parents with children with autism spectrum disorder. The program was based on scientific-based practices and developed to ensure that children exhibit positive behaviors, increase and generalize these behaviors. The exploratory sequential mixed method, which is one of the mixed methods, was used. The study first started with a qualitative method. After taking the opinions of the participants, the data were analyzed and then the quantitative phase started. In the qualitative phase, interviews were conducted with 10 parents using the semi-structured interview form. In the quantitative phase of the study, an experimental design with a pre-test post-test control group was adopted. The sample of the quantitative phase consists of 24 parents with children with Autism Spectrum Disorder (ASD). Research data were analyzed in two stages. Descriptive analysis was used for the analysis of qualitative data. To determine the effectiveness of the Effective Reinforcement Use Parent Education Program developed to increase the positive behavior of students with ASD, the achievement test developed within the scope of the research was applied to the experimental and control groups as pretest and post-test. Considering the sample size and normality distribution test results, the Mann-Whitney $\mathrm{U}$ test and Wilcoxon test conducted to test the significance between the pre-test and post-test scores. In the light of the findings and effect size analysis, the program may be regarded as an effective parent education program.

Keywords: Parent education, Reinforcement, Reinforcer, ASD, Special education, Behavior support.

Citation | Ahsen Ela KIZILKAYA; Hakan SARI (2021) Effectiveness of the Reinforcement Parent Education Program Designed for Parents of Children with Autism Spectrum Disorder on Supporting Positive Behaviours. Asian Journal of Education and Training, 7(2): 103-114

History:

Heceived: 10 February 2021

Revised: 16 March 2021

Accepted: 21 April 2021

Published: 19 May 2021

Licensed: This work is licensed under a Creative Commons

Attribution 3.0 License (cc)

Publisher: Asian Online Journal Publishing Group
Acknowledgement: Both authors contributed to the conception and design of the study. This paper is produced and translated from $\mathrm{PhD}$ thesis entitled "Otizm Spektrum Bozukluğu Olan Çocuğa Sahip Ebeveynlere Yönelik Geliștirilen Pekiștireç Eğitim Programinin Olumlu Davranișlarin Arttirilmasina Etkisi'

Funding: This study received no specific financial support

Funding: This study received no specific financial support.
Competing Interests: The authors declare that they have no conflict of interests.

Transparency: The authors confirm that the manuscript is an honest, accurate, and transparent account of the study was reported; that no vital features of the study have been omitted; and that any discrepancies from the study as planned have been explained.

Ethical: This study follows all ethical practices during writing.

\section{Contents}

1. Introduction

2. Aim.

3. Method 


\section{Contribution of this paper to the literature}

This study examined the effect of the education program developed for parents with children with ASD, based on scientific-based practices and to ensure that children exhibit positive behaviors, increase and generalize these behaviors. In Turkey, there are limited studies to determine the competence levels of the parents with children who need special education and to increase this level in increasing positive behaviors. Parent programs are also limited for families with disabled children. It is thought that this study, which was carried out due to the very limited parent education program in this field, will shed light on future research in the field.

\section{Introduction}

Problem behaviors negatively affect the lives of individuals with autism spectrum disorder and delay the development of interaction and communication skills. Some behaviors can cause physical injuries to the individual and those around him, for example, physical problems such as arms and legs injuries, even loss of sight and hearing can occur in both the individual and the people around him as a result of self-injurious behavior. Problem behaviors negatively affect educational interventions, preventing students with autistic spectrum disorder from interacting with their normally developing peers, causing children to be socially isolated (Sium, 2014). Besides, these behaviors negatively affect the child's academic skills, independence, general development, and create a high level of stress in their parents (Bearss et al., 2015; Strain, Wilson, \& Dunlap, 2011).

Children with developmental delay for any reason are likely to show problematic behavior. Because of these negative behaviors they exhibit, children are at risk of failing at school since they cannot benefit from education and training opportunities sufficiently (Chandler, Dahlquist, Repp, \& Feltz, 1999; Erbaş, 2005). Family attitude and behavior are some of the most important environmental factors related to behavior formation in children with ASD. Ineffective family behaviors such as physical discipline, inconsistency, and lack of affection and warmth are directly related to behavioral problems in children (Dodge \& Pettit, 2003). It can be thought that using physical punishment leads to desired behavior in the short term, but it causes an increase in deviant behavior and aggression in the long term. As the family increases the pressure and control over the child and applies physical punishment, the child has more behavioral disorders. Positive parenting and especially high levels of affection, love, and interest reduce behavioral problems in children (Hoeve et al., 2007).

In family education, it is aimed to inform family members, especially mothers and fathers, and to teach certain skills. When the education process of the child is considered as a whole, family education is of great importance in terms of continuity of education. In terms of the quality of the education to be provided, it is observed that teachers' being experienced and fully equipped in family education positively affects the level of participation in education (Sarı, Atbaşı, \& Cïtil, 2017 ). Family education programs, on the other hand, are systematic educational practices created by relevant experts. Family education programs include helping parents with the acquisition of certain skills, raising their children and the skills to be taught to them. It includes issues such as children's education and other rights, and responsibilities provided to parents. Family education programs and approaches have become increasingly widespread, and the participation of parents with disabled children has increased. Educators, with the help of other personnel, take the responsibility of developing parent education programs that will help the family to develop their skills for the education of children with special needs (Cavkaytar, 2007). While creating the program, the educator should determine the general goals and interests in line with the needs of the families. Family and educators should agree on family education and its results. After determining the goals and clearly defining the desired competencies, families are trained with the simplest training strategies. In the content of the program, families are shown what to do and the opportunity to apply what they have learned (Cavkaytar \& Ozen, 2009).

Due to the increasing prevalence of ASD in recent years, there is a strong need for efficient, cost-effective, and empirically supported interventions for this group. Besides, with the decrease in the average age of diagnosis, the intervention in children with ASD can begin at an early age. Also, best practices suggest that parental involvement is required (Banach, Ludice, Conway, \& Ve Couse, 2010). Considering the diagnosis-specific characteristics and the increasing number of children diagnosed with autism in Turkey, it can be said that educational programs for families are very limited. In this context, this research is expected to contribute to our country in terms of bringing an education program for families with children diagnosed with autism.

Although treatment programming and implementation for school-age children is carried out in schools, parental involvement gives very effective results for children with autism. While the nature of parental involvement can vary widely between programs, families, and children, the most common parental involvement is a parental education model in which parents are taught techniques to work with their children so that the intervention can continue in the absence of the professional person. Parents' participation in education for children with ASD, for whom systematic intensive education is required, is very important in terms of continuity and effectiveness (Banach et al., 2010). The fact that children spend most of their time at home shows us the need to focus on parent education programs. It has been shown that giving correct information to families and teaching them to use effective approaches through parent education increases family harmony and acceptance and improves positive personal, educational, and social results in families with children with ASD (Preece \& Almond, 2008).

The focus of this study is parents with children with ASD. Through the developed program, it is aimed to teach strategies and techniques to increase positive behaviors to parents and to enable the parents to support their child in every environment where the child is with the family. For this goal, the importance of family participation and the necessity of its realization is indisputable. This research is expected to provide a significant contribution to the field regarding that studies are considered to be limited for families who have children with ASD in Turkey. In this study, not only theoretical information was given to families about increasing positive behaviors, but also application examples were presented by the researcher, and application examples were asked to the families. In addition, the permanence test applied three weeks after the end of the education shows that the families continue to maintain their dominance on the subject. From this point of view, it is thought that families will be able to apply the strategies they have learned without expert support in every environment they spend time with their children. 
Parenting education can be an opportunity not only for parents who struggle with their children's behavior or have serious problems but also for parents who want to feel safer, prevent future problems, enjoy being with their children and contribute to the development of family relationships. Empowering the families of children with autism spectrum disorder through education and training is considered the most economical and effective practice (Beaudoin, Sébire, \& Couture, 2014). The education program developed within the scope of this study is expected to make a significant contribution to families in terms of starting to enjoy spending time with their children, developing positive family relations, and preventing possible problems they may encounter.

\section{Aim}

Families with children with normal development can obtain the information they need to reduce their children's negative behaviors or to increase and reinforce their positive behavior by accessing many written and visual resources. Besides, these children can easily get the support they need in acquiring and generalizing these skills in the schools where they are educated. However, it is important to support teaching in the home environment to generalize and increase the skills for individuals with disabilities. The limited support for families who want to increase their child's positive behavior makes them inadequate in terms of the support they will provide to their children. In this context, it is important to provide families with the support they need in increasing the positive behavior of their children. For children with autism spectrum disorder to benefit from behavioral education programs, to continue their general education environment, and to increase their participation in society, it is necessary to develop intervention programs that will increase positive behaviors, and thus they will have an impact on problem behaviors. The research will attempt to determine the effectiveness of the parent education program developed in increasing the positive behaviors of children with autism spectrum disorder.

The purpose of this study is to examine the effect of the education program developed for families with children with ASD, based on scientific-based practices, and to ensure that children exhibit positive behaviors, increase and generalize these behaviors. Determining the level of proficiency on increasing the positive behavior of parents of children with special educational needs and efforts to increase this level is limited in Turkey. Parent programs are also limited for families with disabled children. It is thought that this study, which will be carried out due to the very limited parent education program in this field, will also shed light on future research in the field.

This research was designed as a group parent education, prepared and applied in this direction. All processes, from the design phase to the implementation phase, are organized for the group. When considered from this point of view, this research can serve as an example for experts who plan and implement education for families both in state institutions and private special education institutions. It is thought that this program will serve as a guide for parent education providers in all other institutions.

\section{Method}

This section contains detailed information about the research method, sample, data collection tools, and data analysis.

\subsection{Research Method}

This research aims to evaluate the effect of the effective reinforcement use parent education program developed for parents in increasing the positive behaviors of children with autism spectrum disorder. Under this purpose and data collection processes, the mixed method was used in the research. Researchers collect data using a data collection tool, test, or a behavior checklist. Collecting data may include visiting participants. Data may also be collected through predetermined questions or questions where the individual is allowed to speak openly about a topic. Besides, the type of data analyzed may be numerical information collected by scales or textual information obtained from participants' voice recordings.

In some types of research, both quantitative and qualitative data are collected, analyzed, and interpreted. The method used in these types of research is called the mixed method. In studies using mixed methods, the researcher benefits from both quantitative and qualitative data collection tools (Byrne \& Humble, 2007).

Mixed methods involve combining qualitative and quantitative research data in a study. Qualitative data tend to be open-ended, with no predetermined answers. Quantitative data are usually obtained by data collection tools that contain closed-ended answers such as those found in questionnaires. Mixed methods encourage researchers to collect multiple data formats.

This method, which uses more than one method called the mixed method, allows overcoming the weaknesses of qualitative and quantitative methods by collecting both quantitative and qualitative data. Using qualitative and quantitative data together can be used to check the mutual validity of data sets. A database can help explain the other database (Johnson, Onwuegbuzie, \& Turner, 2004).

Although there are many designs in the field of mixed methods, there are three main models used in social sciences. Parallel mixed method; In this model, the researcher typically uses both data forms at the same time and combines information for interpretation of general results. In the descriptive sequential mixed method, the first method carried out by the researcher is quantitative research. It then analyzes the results and bases them on qualitative research to explain them in more detail. The first quantitative data results are considered descriptive as they are used. Research results are further explained with qualitative data. The first quantitative is then considered to be ordered as it is qualitative.

The exploratory sequential method is in reverse order to the descriptive sequential method. In the exploratory sequential approach, the researcher first starts with qualitative research. It explores the opinions of the participants, then the data are analyzed and turned into a second, quantitative step (Creswell, 2007). In this study, the exploratory sequential mixed method, which is one of the mixed methods, is taken as a basis. The study was first started with a qualitative method. After taking the opinions of the participants, the data were analyzed and then the quantitative phase was started. 


\subsection{Sample}

In the qualitative first phase of this study, in which the mixed method was adopted, 10 families were interviewed within the scope of the need analysis. Therefore, the sample of the qualitative phase of the study consists of these ten families interviewed. There are two different types of datasets, universe, and sample. The universe represents the dataset to which the researcher wishes to generalize the research results; sample, on the other hand, represents a sub-data set participating in the research and selected from the universe suitable for the research purpose. Parents with children with ASD constitute the universe of this research. The sample of the quantitative stage of the research consists of 24 parents with children with ASD determined by a purposeful sampling method from the research universe under the purpose of the research. Twelve parents were determined as the experimental group and the Effective Reinforcement Use Parent Education program developed for parents with children with ASD was applied to increase positive behaviors to these parents. Twelve parents were determined as the control group and these parents were not educated. Pre- and post-tests were applied to both groups.

\subsection{Data Collection Tools}

Two different data collection tools were used in the data collection process of the research. The first is the semi-structured interview form developed by the researcher to determine the educational needs of the families during the development of the education program. The second is the achievement test developed by the researcher to evaluate the effectiveness of the applied program and applied to the participants as a pre-test post-test. Detailed information about data collection tools is presented below.

\subsubsection{Qualitative Data Collection Tool}

The interview is a data collection tool that is carried out through verbal communication and its effectiveness depends largely on the interviewer. The interviewer should have skills such as directing the questions clearly, listening carefully, directing at the appropriate place, and enabling the participant to express their thoughts freely (Cohen, Manion, \& Morrison, 2017). Interview forms may or may not be structured. While unstructured interview forms are a method close to observation, structured interview forms look close to the questionnaire. Semistructured interview forms, on the other hand, provide a balance between the two. Semi-structured interviews allow individuals to express their opinions clearly, so it is important to build mutual trust between the interviewer and the participant. The interviewer should convey this trust to the participant with his speaking style and attitude (Hartas, 2010).

In the semi-structured interview form prepared for this study; There are open-ended questions to determine the training needs of families with children with ASD on reinforcement in increasing positive behavior, frequency of use of reinforcers, types, and schedules. In addition, the interview form consists of two parts. In the first part of the form, there is a family information form. In this section, there is brief information about the research subject to the families, statements stating that their participation in the study is voluntary and expressions of thanks for their participation. In the second part of the interview form, there are interview questions.

\subsubsection{Quantitative Data Collection Tool}

In the quantitative data collection stage of the study, the achievement test, which was developed by the researcher and applied as a pre-test post-test, was used as a data collection tool. Within the scope of the target sentences of the developed parent education program, an achievement test of 40 questions consisting of 4 options was prepared by the researcher. The achievement test prepared was sent to three academicians who are experts in their field for expert opinion. In the success test expert opinion form sent to the experts, they were asked to mark one of the appropriate or not suitable options placed next to the questions, and space was left for them to express their suggestions for the questions they did not find appropriate. After the expert evaluation, the test was finalized and a total of $98(\mathrm{n}=98)$ families were administered to determine the reliability of the developed achievement test, item difficulty, and discrimination indexes. The results resulting from the application are given in Table 1.

Table-1. Item difficulty and item discrimination index.

\begin{tabular}{c|c|c|c|c|c}
\hline Item & $\mathbf{p}$ & $\mathbf{d}$ & $\mathbf{I t e m}$ & $\mathbf{P}$ & $\mathbf{D}$ \\
\hline 1 & 0.56 & 0.46 & 21 & 0.54 & 0.67 \\
\hline 2 & 0.43 & 0.48 & 22 & 0.51 & 0.65 \\
\hline 3 & 0.41 & 0.27 & 23 & 0.51 & 0.73 \\
\hline 4 & 0.57 & 0.81 & 24 & 0.49 & 0.60 \\
\hline 5 & 0.86 & 0.27 & 25 & 0.52 & 0.79 \\
\hline 6 & 0.58 & 0.67 & 26 & 0.45 & 0.56 \\
\hline 7 & 0.44 & 0.58 & 27 & 0.55 & 0.73 \\
\hline 8 & 0.50 & 0.67 & 28 & 0.57 & 0.77 \\
\hline 9 & 0.55 & 0.85 & 29 & 0.54 & 0.75 \\
\hline 10 & 0.43 & 0.65 & 30 & 0.51 & 0.65 \\
\hline 11 & 0.66 & 0.65 & 31 & 0.53 & 0.73 \\
\hline 12 & 0.39 & 0.27 & 32 & 0.47 & 0.44 \\
\hline 13 & 0.30 & 0.23 & 33 & 0.70 & 0.23 \\
\hline 14 & 0.54 & 0.79 & 34 & 0.47 & 0.52 \\
\hline 15 & 0.51 & 0.73 & 35 & 0.52 & 0.46 \\
\hline 16 & 0.46 & 0.67 & 36 & 0.28 & 0.27 \\
\hline 17 & 0.46 & 0.63 & 37 & 0.65 & 0.54 \\
\hline 18 & 0.48 & 0.63 & 38 & 0.54 & 0.83 \\
\hline 19 & 0.54 & 0.63 & 39 & 0.30 & 0.23 \\
\hline 20 & 0.54 & 0.25 & 40 & 0.46 & 0.75 \\
\hline & & & & & \\
\hline
\end{tabular}


When the data were examined, it was seen that the discrimination values of the items in the test were between .44 and .83 and 8 items with a value below .29 should be excluded from the test. Eight items that did not meet the minimum discrimination value were excluded directly from the test. There are 32 questions left in the final form of the achievement test developed. Reliability analysis was performed for the final achievement test consisting of 32 questions and the results are given in Table 2. The final version of the achievement test was applied to 5 families with similar characteristics to the sample. With this pilot application, it is aimed to determine whether there are any unclear questions or unknown words and how many minutes the families can solve this test on average. The test was finalized as a result of the feedback received from the families participating in the application. In the pilot application, it was determined that the families completed the test between 23-30 minutes on average and it was decided to give a 30-minute response time for the achievement test.

Calculation of internal consistency is one of the methods to determine test reliability. KR-20 analysis is the most common analysis used to calculate internal consistency and reliability for achievement tests. The 40-question KR-20 value of the achievement test was determined as 0.93. After the 8 items removed from the test, the KR-20 value of the 32-item achievement test was determined as .97 . The results of the KR-20 analysis performed for the achievement test are given in Table 2 .

\begin{tabular}{c|c|c|c|c|c}
\multicolumn{7}{|c}{ Table-2. Achievement Test KR-20 analysis. } \\
\hline $\mathbf{N}$ & Item & $\mathbf{X}$ & SS & Dif. Mean & rKR20 \\
\hline 98 & 32 & 22.56 & 7.92 & 0.43 & 0.96 \\
\hline
\end{tabular}

\subsection{Data Collection} data.

The data collection process was carried out in two stages: collecting qualitative data and collecting quantitative

\subsubsection{Qualitative Data Collection}

One of the main assumptions of program development is that a solid training program should be based on an analysis of participants' needs. The procedures used to gather information about students' needs are called needs analysis. In other words, needs analysis is a systematic process that determines and evaluates the training required or the needs of an individual or employee, customer, supplier. Needs analysis, as a separate and necessary step in the planning of educational programs, emerged in the 1960 s as part of the systems approach to curriculum development and became part of the education philosophy (Stufflebeam, McCormick, Brinkerhoff, \& Nelson, 1985). The need for educational needs assessment in education planning has been strengthened by the "behavioral goals" movement that measurably indicates all-important goals within the education system. The importance is given to the measurable and content effectiveness of the objectives influenced the emergence of needs analysis as an educational technology form and its use as an education research method (Richards, 2001).

In the development of the program, face-to-face interviews were held with ten families, primarily to determine the educational needs of the families. A semi-structured family interview form was used in these interviews. The data obtained from the interviews were analyzed descriptively within the scope of needs analysis. Questions about the use of reinforcers to increase positive behaviors were asked to the families to measure their level of knowledge on the concepts of reinforcement, reinforcement, reinforcement tariffs, and positive behavior enhancement, revealing their practices in this context and determining their educational needs on these issues. The obtained data were analyzed with the descriptive analysis technique. Program objectives and program content were identified in line with the analysis results. Before the interviews, the families who participated in the research were clearly stated that their names would not be used in any way, and they were informed of the audio recordings, and permission was obtained. The interviews were held between November and December 2019.

\subsubsection{Quantitative Data Collection}

The quantitative data in the study were collected by the achievement test. The achievement test was applied to participating families in both control and experimental groups before the application of the education program. The applied achievement test results were transferred to the computer as a pre-test. After the application, the achievement test was applied to both groups as a post-test, and the data obtained were transferred to the computer environment for statistical analysis. Before the achievement test and program implementation, consent forms were obtained from the families indicating that they voluntarily participated in the study. Success test applications were applied under the supervision of the researcher. Participants were reminded that for data validity and reliability, they should answer sincerely while solving the achievement test. Before the achievement test was applied as a pretest and a post-test, the necessary item analyzes were made and detailed information about this was given under the relevant heading. As a result, the achievement test developed by the researcher was applied to the experimental and control groups as a pre-test before applying for the effective reinforcement use parent education program. The program was implemented only to the experimental group and the post-training achievement test was applied to both groups again. The quantitative data obtained through the achievement test were analyzed using statistical analysis methods through the SPSS software. The data relating to the analysis results were presented and interpreted in the form of tables.

\subsection{Data Analysis}

The research data were analyzed in two stages. Descriptive analysis was used for the analysis of qualitative data, and a statistical analysis program for social sciences (SPSS) was used for the analysis of quantitative data.

\subsubsection{Qualitative Data Analysis}

The descriptive analysis provides simple summaries of the data. Along with simple chart analysis, they form the basic virtual component of any qualitative data analysis. With descriptive analysis, the individual explains what the data is or what it shows. The description of the data is necessary to determine the normality of the distribution, 
since the nature of the techniques to be applied for inferential analysis of the data depends on the characteristics of the data, it is necessary to explain the data. This study was carried out by adopting a mixed-method, and firstly, semi-structured face-to-face interviews were conducted with the families to determine the educational needs of the families, and the data obtained were analyzed with descriptive content analysis. The descriptive analysis method was preferred because it offers real-time data capture and analysis. The descriptive analysis provides an explanatory summary of the information content arranged to best fit the data (Sandelowski, 2000).

The reasons why this method is preferred; first, it provides a rich description of families' experiences on the subject; second, it determines and explains the effectiveness of the program content and; Third, it identifies the elements of individual and interpersonal experiences that cannot be measured by a questionnaire (Hsieh \& Shannon, 2005). Descriptive content analysis is a widely used method of analysis in many disciplines, including education, psychology, and social sciences. It is a preferred analysis method especially in qualitative research or in analyzing qualitative data. Descriptive analysis in educational research not only reveals the complexity of content, examines how learning takes place in general or what factors affect it, but also enables a deeper study and understanding of individual learners' educational needs, behaviors, and experiences. Descriptive analysis, which is the preferred analysis method in qualitative research, is used to analyze semi-structured face-to-face interviews (Loeb et al., 2017).

\subsubsection{Quantitative Data Analysis}

The evaluation of the effectiveness of the program determines the causal effects of the program. It involves measuring whether the program is achieving its intended results, that is, program results. Program goals should change the status or social circumstances of the sample. Program outcomes are observed characteristics of the target sample or social conditions. There are two types of outcomes, outcome level and outcome change, which are also associated with program impact. Outcome level refers to the state of an outcome over a while. Outcome change refers to the difference between outcome levels at different points in time. Program effect refers to the portion of an outcome change that can be uniquely associated with a program as opposed to the effect of another factor. Outcome evaluation is to represent the conditions defined as outcomes through observable indicators that change systematically with the change or difference in these conditions. Impact assessment is a systematic way of assessing the extent to which a program achieves its intended outcomes (Rossi, Peter, Lipsey, \& Freeman, 2003).

The data obtained from the achievement test applied before and after the implementation of the education program were analyzed by SPSS 23 computer software. Statistical analyzes were performed using the MannWhitney $\mathrm{U}$ and Wilcoxon tests to determine whether there was a significant relationship between the pre-test and post-test scores of the experimental and control groups and whether there was a significant relationship between the scores of the groups. Before performing data analysis, Kolmogorov Smirnov and Shapiro-Wilk normality distribution tests were performed to decide on the statistical test to be applied, and the appropriate parametric or non-parametric tests were selected according to the results.

Table-3. Normality distribution test analysis results

\begin{tabular}{|c|c|c|c|c|c|c|}
\hline \multirow[b]{2}{*}{ Group } & \multicolumn{3}{|c|}{ Kolmogorov-Smirnov $^{\mathrm{a}}$} & \multicolumn{3}{|c|}{ Shapiro-Wilk } \\
\hline & Statistic & df & Sig. & Statistic & df & Sig. \\
\hline Control & 0.321 & 12 & 0.001 & 0.808 & 12 & 0.012 \\
\hline Experimental & 0.268 & 12 & 0.017 & 0.885 & 12 & 0.103 \\
\hline
\end{tabular}

When Table 3 was examined, it was found that the data did not show a normal distribution. The Wilcoxon test, which is used to compare two measurements from the same sample but not showing a normal distribution, was used to analyze the pre-test and post-test scores of the experimental group and the pre-test post-test scores of the control group to evaluate the significant difference within the group. In order to test the significant difference between groups, the Mann-Whitney $\mathrm{U}$ test, which is used to compare two measurements from different samples but not showing a normal distribution, was used to analyze the pre-test and post-test scores of the experimental group and the control group.

\section{Findings}

In this section, the findings regarding the research results are given in line with the sub-questions of the research.

\subsection{Findings Regarding the First Research Question}

The first research question of the research is the opinions of the parents on the educational needs of reinforcement and the use of reinforcers to increase the positive behaviors of children with ASD in their daily life. Findings reached within the scope of this purpose are included under this heading.

\subsubsection{Findings Regarding Parental Competencies}

In order to determine the content of the reinforcing parent education program developed to increase the positive behaviors of children with ASD, interviews were conducted with ten parents using a semi-structured interview method within the scope of needs analysis. The data obtained from the interviews were analyzed with the descriptive analysis technique and an answer was sought for the first research question of the study, what is the need for the parent education program.

All of the parents interviewed within the scope of the needs analysis $(100 \%)$ find themselves insufficient in the use of reinforcement and reinforcement in increasing positive behaviors. Some of the parents stated that they heard the names of these concepts and read written materials about them, but they still could not have detailed information. Some parents say they have almost no information, while some parents say they have heard of this 
concept for the first time. Families who participated in the interview shared a common view that they did not see themselves as knowledgeable about this issue.

\subsubsection{Findings Regarding Parents' Demand for Education}

Ten parents $(100 \%)$ who participated in the interviews stated that they would like to receive education in reinforcement and the use of reinforcers to increase positive behavior. All of the parents shared a consensus that such an education would benefit them and would be a support for many difficult situations they experienced. Parents stated that they were looking for opportunities to participate in all kinds of education that would be beneficial for both their children and themselves, that they had great difficulties in this area where they lived, and therefore they wanted to participate in such a great education. Parents expressed their desire to participate in this education as they thought that it would be beneficial for them.

\subsubsection{Findings Regarding Parents' Vieres on the Content of Education}

Within the scope of the needs analysis conducted to determine the content of the education program, semistructured interviews and interviews were conducted with ten families, and the questions were asked to the families on what subjects they would like to receive education in a training about the use of reinforcers and reinforcement. Detailed data on the descriptive analysis results of the data obtained from the participants' answers regarding this question are given in Figure 1. When the relevant figure is examined, all parents stated that they need education on reinforcement and reinforcer, nine parents (90\%) on reward and punishment, eight parents (80\%) on primary and secondary reinforcers, and finally $70 \%$ of parents on reinforcement schedules. Although the parents have very limited knowledge about the subjects and concepts included in the reinforcement, they also stated that they are confused about the subjects they have and that they cannot use them. Parents shared their views that they had difficulties in using the concepts of reward and punishment, had wrong experiences in this regard, and that more problems emerged due to these experiences.

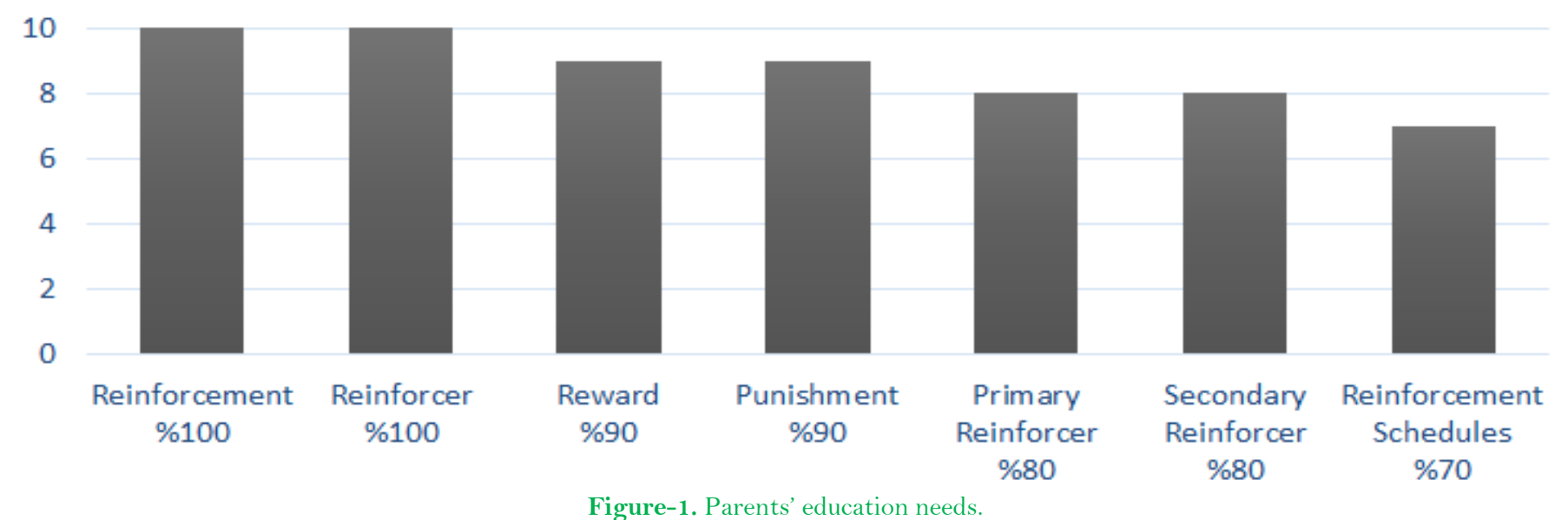

\subsection{Findings Regarding the Second Research Question}

The question of whether there is a statistically significant difference between the pre-test scores of the experimental group and the control group constitutes the second sub-objective of the research. Findings regarding this research question are given under this title in Table 4.

\begin{tabular}{l|l|l|l|l|l|l|l}
\multicolumn{7}{c}{ Table-4. Mann whitney-U test analysis results regarding experimental-control group pre-test scores. } \\
\hline Test & Group & N & S. Ort. & S. Top. & Z & U & P \\
\hline \multirow{2}{*}{ Pre-test } & Experimental & 12 & 11.08 & 133 & & & \\
\cline { 2 - 9 } & Control & 12 & 13.92 & 167 & -0.991 & 55 & 0.347 \\
\hline Note: $\mathrm{p}<0.05$.
\end{tabular}

To determine the effectiveness of the Education Program developed to increase the positive behavior of students with ASD, the achievement test developed within the scope of the research was applied to the experimental and control groups as a pre-test before the education. The results of the Mann-Whitney U test conducted to test the significance of the pre-test scores between the groups. According to the Mann-Whitney-U Test, the average of the ranks in the experimental group was found to be 11.08 and the total of the ranks was 133. The mean of the ranks in the control group was 13.92, and the total of the rows was 167 . The U value was 55 and the significance value was calculated as $0.347(\mathrm{p}<0.005)$.

The $\mathrm{p}$-value $(\mathrm{p}=.347)$ obtained as a result of the analysis performed between the two groups reveals that there is no significant difference between the means of the groups. According to the analysis results of the pre-test scores performed before the application, the skills of reinforcement and use of reinforcement in increasing positive behaviors of the parents in the experimental group and the control group are close to each other. This finding supports the necessity of not having any difference between groups at the beginning stage to observe the effect of the independent variable during the experimental process.

\subsection{Findings Regarding the Third Research Question}

The findings regarding whether there is a statistically significant difference between the pre-test post-test scores of the control group are given in Table 5 . 


\begin{tabular}{c|c|c|c|c|c|c}
\multicolumn{6}{c}{ Table-5. Wilcoxon test analysis results regarding the control group pre-test post-test scores. } \\
\hline Group & Test & N & R. Mean & R. Total & Test statistics & P \\
\hline \multirow{2}{*}{ Control } & Pre-test & 12 & 5.21 & 36.50 & & \\
\cline { 2 - 8 } & Post-test & 12 & 4.25 & 8.50 & -1.660 & 0.97 \\
\hline
\end{tabular}

To determine the effectiveness of the Education Program, the achievement test developed within the scope of the research was applied to the control group as pre-test and post-test before and after the education. Considering the sample size and normality distribution test results, the average of the pre-test ranks was 5.21 and 36.50 was found in the Wilcoxon test results, which were conducted to test the significance between pre-test and post-test scores within the group. The posttest mean of ranks was 4.25 and the total of ranks was 8.5.

According to the test results, the WT value-1.660 was calculated as the significance value of $0.97(\mathrm{p}<0.005)$. The $\mathrm{p}$-value $(\mathrm{p}=.97)$ obtained as a result of the analysis between the two tests reveals that there is no significant difference between the control group pretest and posttest mean scores. According to the results of the Wilcoxon test, the skills of reinforcement and the use of reinforcers in increasing positive behaviors of the parents in the control group are close to each other before and after the application. This can be explained by the lack of education of the control group.

\subsection{Findings Regarding the Fourth Research Question}

The achievement test developed within the scope of the research was applied to the experimental and control groups as a post-test. The results of the Mann-Whitney $U$ test conducted to test the significance between the posttest scores between the groups, taking into account the sample size and normality distribution test results, are given in Table 6. According to the Mann-Whitney-U Test, the average of ranks in the experimental group was 18.50 , and the total of rows was 222. The mean of ranks in the control group was 6.5 , and the total of rows was 78 . The $U$ value was calculated as, 000 and the significance value as, $000(\mathrm{p}<0.005)$. The $\mathrm{p}$-value $(\mathrm{p}=.000)$ obtained as a result of the analysis performed between the two groups reveals that there is a significant difference between the means of the groups.

According to the analysis results of the post-test scores performed after the application, the skills of reinforcement and use of reinforcement in increasing positive behaviors of the parents in the experimental group and the control group are quite distant from each other. This finding shows that the parent education program developed within the scope of the research was effective in favor of the experimental group that was applied. To reveal the effect size, Cohen's $d$ value and effect size $r$ value analysis were performed utilizing mean scores and standard deviations. The effect size value was determined as $r=0.87$ and $d=3.59$. In the light of these findings, it can be said that the program is a very effective education program.

\begin{tabular}{c|c|c|c|c|c|c|c|c}
\multicolumn{8}{c}{ Table-6. Experimental-control group post-test mann whitney-U test analysis results. } \\
\hline Test & Group & $\mathbf{N}$ & S. Ort. & S. Top. & $\mathbf{Z}$ & $\mathbf{U}$ & $\mathbf{p}$ & $\mathbf{R}$ \\
\hline Post-test & Experimental & 12 & 18.50 & 222 & & & & \\
\cline { 2 - 10 } & Control & 12 & 6.5 & 78 & -4.771 & 0.000 & 0.000 & 0.87 \\
\hline Note: $\mathrm{p}<0.05$.
\end{tabular}

\subsection{Findings Regarding the Fifth Research Question}

The achievement test developed within the scope of the research was applied to the experimental group as a pre-test and a post-test before and after the education. According to the results of the Wilcoxon test conducted to test the significance between the pre-test and post-test scores within the group, considering the sample size and normality distribution test results, the pre-test ranks mean was 6.5 and the total of the ranks was 78 . The posttest mean of ranks was 00 and the total of ranks was 00.

According to the test results, the WT value-3,072 significance value was calculated as $002(\mathrm{p}<0.05)$ in Table 7. The $\mathrm{p}$-value $(\mathrm{p}=.002)$ resulting from the analysis performed between the two tests reveals a significant difference between the experimental group pre-test and post-test mean scores. According to the results of the Wilcoxon test, the skills of the parents in the experimental group regarding the use of reinforcement and reinforcement in increasing positive behaviors before and after the application are quite far from each other. This finding can be explained by the fact that the training activities carried out with the experimental group participating in the education practice are quite effective. As a result of the calculations carried out to determine the effect size, it was determined as $r=0.90$. The measure of the effectiveness of the effect is called the effect size. The difference between the averages of two events or groups is called the effect size. According to this result, it can be found that the education program implemented has a very high effect size.

Table-7. Experimental group pre-test post-test wilcoxon test analysis results.

\begin{tabular}{c|c|c|c|c|c|c|c}
\hline Group & Test & N & R. Mean & R. Total & Test Stats & P & R \\
\hline \multirow{2}{*}{ Experimental } & Pre-test & 12 & 6.5 & 78 & & & \\
\cline { 2 - 9 } & Post-test & 12 & 0.00 & 0.00 & -3.072 & 0.002 & 0.90 \\
\hline
\end{tabular}

Note: $\mathrm{p}<0.05$.

\subsection{Findings Regarding the Sixth Research Question}

The achievement test developed within the scope of the research was applied as a retention test three weeks after the application to the experimental group on which the education program was applied. After the program implementation, the results of the experimental group post-test and the permanence test were compared to evaluate the permanence of the reinforcing parent education program within the group. 


\begin{tabular}{c|c|c|c|c|c|c}
\multicolumn{2}{c}{ Table-8. Analysis results of wilcoxon test regarding experimental group post-test and retention test scores. } \\
\hline Group & Test & N & R. mean & R. Total & Test Stats & P \\
\hline \multirow{2}{*}{ Experimental } & Post-test & 12 & 2.75 & 5.50 & & \\
\cline { 2 - 8 } & Retention & 12 & 2.25 & 4.50 & -0.184 & 0.854 \\
\hline
\end{tabular}

Note: $\mathrm{p}<0.05$.

Considering the sample size and normality distribution test results, the posttest mean of ranks was 2.75 and the total of ranks was found to be 5.50 for the Wilcoxon test results, which were conducted to test the statistical significance between the posttest and retention test scores within the group in Table 8 . The permanence test was determined as the average of the ranks as 2.25 and the total of the rows as 4.50. According to the test results, the WT value, -184 significance value was calculated as $854(\mathrm{p}<0.05)$. The $\mathrm{p}$-value $(\mathrm{p}=.854)$ resulting from the analysis between the two tests reveals that there is no significant difference between the experimental group posttest and retention test mean scores.

\section{Discussion}

The study aims to develop the program for families with children with autism and to determine the effect of the developed program on increasing positive behaviors in the children of families. In the study, there were a total of 24 parents, 12 parents in the experimental group and 12 parents in the control group. Before the program, 10 parents were interviewed in line with the needs analysis. It was stated to both the participants who participated in the interview and the families before the education that there was a criterion for having a child with autism in participating in the study, and accordingly, families were selected for the study. During the education phase, the families were reminded that the education given was carried out within the scope of research and they were asked to show sensitivity for full participation in the sessions. One of the biggest problems encountered in group education, the problem of determining the appropriate time for everyone has been overcome with the dedication of the parents and the researcher's effort to determine the appropriate time for each parent, and the support of providing transportation to the education place. The participants attended the program with great care. The only problem participants experienced in participating in the program was difficulty in finding a place to leave their children or a caregiver during the program.

When parents are actively involved in the parenting education process, including the choice of program, they are more willing to receive education (Kuhar \& Reiter, 2013). The parent education program developed within the scope of this study was developed based on the needs analysis. Therefore, the content of the program has been determined in line with the needs of the parents. Within the scope of the research, it was revealed that the families did not have information about reinforcement and were willing to receive education on this subject within the scope of the interviews made with the families in the period before the education program was prepared to reveal their educational needs. The families stated that they did not have both conceptual and practical knowledge and skills related to the subject chosen for education, and all of them expressed positive opinions about receiving education on this subject. In parallel with the results of the interviews, families participated in the education program voluntarily and enthusiastically.

Parent education provides opportunities to reveal or improve the skills that parents have. Parents may need some educational support to better support the child both in social life and academic life. The fact that the first educators of children are parents and this is a situation that lasts throughout their lives are the most important reasons for the need for parent education. In this education program, parents have increased their competence in using reinforcers and the increase in the positive behaviors of their children will help to make important contributions to the development of children.

According to Fisher and Gilliam (2012) the behavior management approach uses behavior change including reinforcement, punishment, and modeling based on social learning theory. Reinforcement is provided depending on the appropriate behavior. Denial of social interest (eg ignoring the child) or punishment is given in response to inappropriate behavior. Parents try to control the child; the child resists this, the parents become more deterrent; the child becomes more resistant or unruly; the parents soften, but the child continues the destructive behavior. It is easy and possible for parents and children to get caught in this confrontational and destructive cycle. Behavior management approaches try to break this cycle with sensible behavior management tools. The behavior management approach was used in the development of this education program. After their positive behavior, families were taught how to reinforce their children. Families often focus on their children's problematic or inappropriate behaviors. Reinforcing appropriate behaviors contributes to both the increase of these behaviors and the decrease of inappropriate behaviors. After the parents learned strategies to increase positive behaviors, they focus on the behaviors that their children can do rather than what their children cannot do, and they pay more attention to reinforcing these behaviors. Stating that parents have learned this attitude has an important place in terms of practice.

The parent education program presented in the research was given through group education. The greatest benefit for the researcher of choosing group education within the scope of this program is that more than one parent can be trained at the same time, thus saving time and energy. At the same time, group education is of great importance for parents participating in education to learn from each other, to understand that they are not alone in the problems they encounter for similar reasons and results, to support each other in line with their own experiences and to convey their knowledge and to feel stronger (Cavkaytar, 1998). However, while group programs provide significant advantages in terms of cost-effectiveness, they can also provide additional benefits to parents in terms of social support and stress reduction (Farmer \& Reupert, 2013). Considering this context, the education program provided many benefits in terms of supporting families, making them feel better, and accessibility to more than one family in the same period for the researcher.

Thanks to learning strategies that improve their children's behavior, many parents may experience a reduction in some aspects of parental stress. This is especially true when parents are able to develop an increased sense of self-efficacy and parent education programs are carefully designed to naturally fit into daily routines. This concept is very important for parents of children with ASD. Since numerous studies reveal that parents of children with 
autism have higher levels of stress than parents of children with other developmental retardation or other types of disability (Al-Khalaf, Dempsey, \& Dally, 2014; Baker-Ericzén, Brookman-Frazee, \& Stahmer, 2005; Davis \& Carter, 2008; Estes et al., 2013). In this context, considering that the knowledge and skills acquired to increase positive behaviors will contribute to the management and reduction of many difficult behaviors done by children, a decrease in parental stress is an expected result. During the education program, the strategies that parents learned about increasing positive behaviors also contributed positively to their communication with their children, they expressed their opinion that their stress levels decreased and they felt more comfortable.

Considering the data obtained during the research process and the observations and information obtained by the researcher during the education, it was seen that the families had different attitudes about applying reinforcement due to both incomplete or incorrect information and negative attitudes before the education was implemented. If we list these behaviors;

1) Parents had very limited knowledge and skills about the concept and use of reinforcement,

2) Since parents do not know the basic principles that should be applied for the permanence of positive behaviors of children, they have problems in the permanence of these behaviors,

3) Parents tended to misinform and practice about reward and punishment,

4) As the parents did not know the principle of not creating saturation in the child while reinforcing, they were constantly using the same and high amount of reinforcement.

5) Parents do not give enough information to the child about what they reinforce. Considering that using reinforcement is sufficient, they do not emphasize with a clear expression to the child why she uses reinforcement.

6) Parents mostly consider the development of their children in the academic field; therefore, they tend to apply reinforcement in this area, but the most common complaint is the failure to achieve permanence in the positive behavior of their children.

In this study, parents stated that they realized the wrong practices they made in supporting and increasing positive behaviors of their children during the education process and at the end. The scores they obtained in the achievement test and retention test also show that they have gained the necessary knowledge and application skills on these issues. Parents underlined that they started to apply the knowledge they gained in the education sessions and proceeded positively in this regard, especially before each session. Again, the evaluations made during the sessions and the observations obtained from the application examples made by the educator showed that the program contributed to the parents in using reinforcers effectively and increasing positive behaviors.

Sucuoğlu (1996) reported that one of the most important benefits of family education programs is that families feel more competent than before and approach their children more positively. Parents also understood that the knowledge and strategies they learned to increase positive behaviors within the scope of the program are extremely easy to apply in daily life, practical, and functional. In this way, their belief and confidence in themselves increased, and this effect of the program on parents also provided positive support for the confrontational and resilient communication they had established with their children before.

Tavil and Karasu (2013) stated that the target group in the majority of family education studies is mothers. In addition, they expressed that it would be appropriate to plan further studies to include other members of the family, as mothers' more active involvement in business life in today's conditions will make it almost compulsory for other members of the family to participate more in the family education programs. In the family education program, mothers constitute the majority of the participants, supporting this study. With the efforts of the researcher, fathers were included in the study, and their participation in the education was ensured. The fact that mothers are more willing to participate in education compared to fathers can be interpreted as having more time with their children compared to fathers and finding the time to participate in education more comfortably.

The concept of the benefit of parents' active participation in the educational process has been voiced for over four decades. As parents spend more time with their children during the day, in the evenings, and on the weekends than any specialist, they can intervene "around the clock". Besides, parental education has a greater impact on the child in generalization, given that experts often see children in a limited number of settings, such as a practice room, and that parents provide their children with learning opportunities in many natural settings (Al-Khalaf et al., 2014; Brookman-Frazee, Drahota, \& Stadnick, 2012; Finders, Díaz, Geldhof, Sektnan, \& Rennekamp, 2016; Hieneman, Childs, \& Sergay, 2006; Johnson \& Myers, 2007; Prata, Lawson, \& Coelho, 2018). In this context, the inclusion of parents in the education process of their children can increase the child's progress rate and speed by increasing the support the child has throughout the day. The strategies that parents learned effectively in increasing positive behaviors were given to their children with autism through this program. Permanence increases as parents have the competence to apply these strategies they learn in every environment and time they spend with their children.

\section{Conclusion}

In this study, the effect of the reinforcement education program for parents with children with ASD, which was developed to increase the positive behaviors of children with autism spectrum disorder, was examined and the results obtained are listed below.

1) All of the parents who participated in the research find themselves inadequate in the use of reinforcement in increasing the positive behaviors of children with autism spectrum disorder. Parents' knowledge of reinforcement and use of reinforcement is based on inadequate and theoretical definitions. Parents generally confuse the concepts of negative reinforcement and punishment, reward and reinforcer.

2) All of the parents need education on the use of reinforcement to increase positive behaviors of children with autism spectrum disorder. Parents are willing to receive education on this subject.

3) Parents with children with ASD have problems in the application of reinforcement and the use of reinforcers in a common and standardized application competency in increasing positive behaviors.

4) The post-test results of the Effective Reinforcement Parent Education Program developed for parents with children with ASD in increasing the positive behaviors of children with ASD created a statistically significant difference between the experimental group and the control group. After the education, it was concluded that the parents in the experimental group were more successful than the control group in the use of effective reinforcers. 
5) Effective Reinforcement Parent Education Program developed to increase the positive behaviors of children with ASD created a statistically significant difference between the pre-test post-test scores of the experimental group. It was concluded that the parents in the experimental group after the education were more successful in the use of effective reinforcers compared to their pre-education situations.

6) Effective Reinforcement Parent Education Program yielded effective results in the experimental group in the ability to use reinforcement and to determine reinforcement schedules effectively.

\section{Implications}

1) The effectiveness of the reinforcement education program developed for parents with children with ASD in increasing the positive behaviors of children with ASD can be evaluated by applying it to larger samples.

2) The parent education program, the effect of which was tested with this research, can be applied in Guidance and Research Centers. Parent education programs can be organized by lifelong education or special education application and research centers within the body of the university to increase positive behaviors for parents with children with ASD,

3) The education program can also be applied to parents with children with normal development.

4) The education program developed within the scope of the research can be taught to educators and experts who are interested or willing, through events such as meetings and seminars to be held.

5) The program, developed for parents with children with ASD, can also be adapted for families with children with different types of disabilities.

6) By developing and increasing sample videos prepared by the researcher or used by the researcher, the program can be enriched in terms of implementation.

\subsection{Implications for Further Research}

1) This study focused on how families participating in the program were affected by the program; it was checked whether the parents acquired information and applied it. It is important to examine how the children with ASD, which is the application source of the education, are affected by the education given, in terms of contributing to the effectiveness of the program. Therefore, in further studies, a re-evaluation can be made by looking at the effect of the program on children.

\section{References}

Al-Khalaf, A., Dempsey, I., \& Dally, K. (2014). The effect of an education program for mothers of children with autism spectrum disorder in Jordan. International Journal for the Advancement of Counselling, 36(2), 175-187. Available at: https://doi.org/10.1007/s10447-0139199-3.

Baker-Ericzén, M. J., Brookman-Frazee, L., \& Stahmer, A. (2005). Stress levels and adaptability in parents of toddlers with and without autism spectrum disorders. Research and Practice for Persons with Severe Disabilities, 30(4), 194-204. Available at: https://doi.org/10.2511/rpsd.30.4.194.

Banach, M., Ludice, J., Conway, L., \& Ve Couse, L. (2010). Family support and empowerment: Post autism diagnosis support group for parents. Social Work with Groups, 33(1), 69-83.

Bearss, K., Johnson, C., Smith, T., Lecavalier, L., Swiezy, N., Aman, M., ... Minshawi, N. (2015). Effect of parent training vs parent education on behavioral problems in children with autism spectrum disorder: A randomized clinical trial. Jama, 313(15), 1524-1533. Available at: https://doi.org/10.1001/jama.2015.3150.

Beaudoin, A. J., Sébire, G., \& Couture, M. (2014). Parent training interventions for toddlers with Autism Spectrum disorder. Autism Research and Treatment, 2014(1), 1-15. Available at: https://doi.org/10.1155/2014/839890.

Brookman-Frazee, L. I., Drahota, A., \& Stadnick, N. (2012). Training community mental health therapists to deliver a package of evidencebased practice strategies for school-age children with autism spectrum disorders: A pilot study. Journal of Autism and Developmental Disorders, 42(8), 1651-1661. Available at: https://doi.org/10.1177/10983007040060040201.

Byrne, J., \& Humble, A. (2007). An introduction to mixed method research. Atlantic Research Centre for Family-Work Issues, 2007(1), 1-4.

Cavkaytar, A. (1998). Effectiveness of a family education program in teaching the mentally disabled self-care and home skills. Anadolu University, Institute of Social Sciences, Published Doctoral Thesis, Eskişehi.

Cavkaytar, A. (2007). Turkish parents as teachers: Teaching parents how to teach self-care and domestic skills to their children with mental retardation. Education and Training in Developmental Disabilities, 42(1), 85-93.

Cavkaytar, A., \& Ozen, A. (2009). Akçamete, G. (Ed.) In family participation and education, Students with special needs in general education schools and special education (pp. 169-198). Ankara: Kök Publishing.

Chandler, L. K., Dahlquist, C. M., Repp, A. C., \& Feltz, C. (1999). The effects of team-based functional assessment on the behavior of students in classroom settings. Exceptional Children, 66(1), 101-121. Available at: https://doi.org/10.1177/001440299906600107.

Cohen, L., Manion, L., \& Morrison, K. (2017). Research methods in education. London: Routledge.

Creswell, J. W. (2007). Research design: Qualitative, quantitative and mixed method aproaches. Los Angeles: SAGE Publications.

Davis, N. O., \& Carter, A. S. (2008). Parenting stress in mothers and fathers of toddlers with autism spectrum disorders: Associations with child characteristics. Journal of Autism and Developmental Disorders, 38(7), 1278-1291. Available at: https://doi.org/10.1007/s10803-007-05 12-z.

Dodge, K. A., \& Pettit, G. S. (2003). A biopsychosocial model of the development of chronic conduct problems in adolescence. Developmental Psychology, 39(2), 349-371. Available at: https://doi.org/10.1037/0012-1649.39.2.349.

Erbaş, D. (2005). Positive behavioral support. Ankara University Faculty of Educational Sciences Special Education Journal, 6(1), 1-25. Available at: 10.1501/Ozlegt_0000000087.

Estes, A., Olson, E., Sullivan, K., Greenson, J., Winter, J., Dawson, G., \& Munson, J. (2013). Parenting-related stress and psychological distress in mothers of toddlers with autism spectrum disorders. Brain and Development, 35(2), 133-138. Available at: https://doi.org/10.1016/j.braindev.2012.10.004.

Farmer, J., \& Reupert, A. (2013). Understanding Autism and understanding my child with Autism: An evaluation of a group parent education program in rural Australia. Australian Journal of Rural Health, 21(1), 20-27. Available at: https://doi.org/10.1111/ajr.12004.

Finders, J. K., Díaz, G., Geldhof, G. J., Sektnan, M., \& Rennekamp, D. (2016). The impact of parenting education on parent and child behaviors: Moderators by income and ethnicity. Children and Touth Services Revierw, 71, 199-209. Available at: https://doi.org/10.1016/j.childyouth.2016.11.006.

Fisher, P. A., \& Gilliam, K. S. (2012). Research into theory into practice: An overview of family based interventions for child antisocial behavior developed at the oregon social learning center. Clinica y Salud, 23(3), 23. Available at: https://doi.org/10.5093/cl2012a16.

Hartas, D. (2010). Educational research and inquiry: Qualitative and quantitative approaches. London: Continuum.

Hieneman, M., Childs, K., \& Sergay, J. (2006). Parenting with positive behavior support: A practical guide to resolving your child's difficult behavior. Baltimore: Brookes Publishing. 
Hoeve, M., Smeenk, W., Loeber, R., Stouthamer-Loeber, M., van der Laan, P. H., Gerris, J. R., \& Dubas, J. S. (2007). Long-term effects of parenting and family characteristics on delinquency of male young adults. European Journal of Criminology, 4(2), 161-194. Available at: https://doi.org/10.1177/1477370807074854.

Johnson, R. B., Onwuegbuzie, A. J., \& Turner, L. A. (2004). Mixed methods research: A research paradigm whose time has come. Educational Researcher, 33(7), 14-26. Available at: https://doi.org/10.3102/0013189X033007014.

Johnson, C. P., \& Myers, S. M. (2007). Identification and evaluation of children with autism spectrum disorders. PEDIATRICS, 120(5), 11831215. Available at: https://doi.org/10.1542/peds.2007-2361.

Kuhar, M., \& Reiter, H. (2013). Towards a concept of parental authority in adolescence On the concept of parental authority in adolescence. Journal of Autism and Developmental Disorders, 3(2), 135-155.

Loeb, S., Dynarski, S., McFarland, D., Morris, P., Reardon, S., \& Reber, S. (2017). Descriptive analysis in education: A guide for researchers. U.S. Department of Education, Institute of Education Sciences. National Center for Education Evaluation and Regional Assistance NCEE 2017-4023. Retrieved from: https://files.eric.ed.gov/fulltext/ED573325.pdf.

Prata, J., Lawson, W., \& Coelho, R. (2018). Parent training for parents of children on the autism spectrum: A review. International Journal of Clinical Neurosciences and Mental Health, 5(3), 1-8.

Preece, D., \& Almond, J. (2008). Supporting families with children on the autism spectrum: Using structured teaching approaches in the home and community. Good Autism Practice (GAP), 9(2), 44-53.

Richards, J. C. (2001). Needs analysis in J. C. Richards (Ed.), Curriculum Development in Language Teaching (pp. 51-89). Cambridge: Cambridge University Press.

Rossi, P. H., Peter, H., Lipsey, M. W., \& Freeman, H. E. (2003). Evaluation: A systematic approach. London: Sage.

Sandelowski, M. (2000). Whatever happened to qualitative description? Research in Nursing \& Health, 23(4), 334-340. Available at: https://doi.org/10.1002/1098-240X(200008)23:4<334::AID-NUR9>3.0.CO;2-G.

Sarı, H., Atbaşı, Z., \& Cïtil, M. (2017). Determining the proficiency of teachers working in special education and rehabilitation centers on family education. Ahi Evran University Journal of Kirşehir Education Faculty, 18(3), 668-684.

Sium, B. (2014). Parent involvement in education. In How Black and Working Class Children Are Deprived of Basic Education in Canada (pp. 81-103). Rotterdam: Sense Publishers.

Strain, P. S., Wilson, K., \& Dunlap, G. (2011). Prevent-teach-reinforce: Addressing problem behaviors of students with autism in general education classrooms. Behavioral Disorders, 36(3), 160-171. Available at: https://doi.org/10.1177/019874291003600302.

Stufflebeam, D. L., McCormick, C. H., Brinkerhoff, R. O., \& Nelson, C. O. (1985). Conducting educational needs assessments. Içinde Conducting Educational Needs Assessments. Netherlands: Springer.

Sucuoğlu, B. (1996). Parental involvement in inclusion programs. Ankara University Faculty of Educational Sciences Special Education Journal, 2, 25-43. Available at: 10.1501/Ozlegt_0000000032.

Tavil, Y. Z., \& Karasu, N. (2013). Family education studies: A review and meta-analysis example. Education and Science, 168(38), 85-95. 